\title{
AVALIAÇÃO DE DIFERENTES ROTAS DE PRODUÇÃO DE ETANOL BIOCOMBUSTÍVEL A PARTIR DE RESÍDUOS DE INDÚSTRIAS LÁCTEAS ${ }^{1}$
}

Dile Pontarolo Stremel ${ }^{2}$, Luis Fernando Souza Gomes ${ }^{3}$, Arnildo Albiero ${ }^{4}$, Giovane Andrei Kulkamp ${ }^{5}$, Daniela Rodrigues Pereira ${ }^{6}$

${ }^{1}$ Aceito para publicação, $1^{\circ}$ trimestre de 2013.

2 Professor Adjunto II da Universidade Federal do Paraná, Setor Palotina, , atua em disciplinas profissionalizantes dos Cursos de Tecnologia em Biotecnologia e Biocombustíveis. Coordena Pesquisa relacionada à produção e otimização de processos fermentativos e enzimáticos e desempenho de Biorreatores.

${ }^{3}$ Professor Assistente II da Universidade Federal do Paraná, Setor Palotina, atua em disciplinas básicas e profissionalizantes dos Cursos de Tecnologia em Biotecnologia, Biocombustíveis e Agronomia. Coordena atualmente projetos de Pesquisa envolvendo produção de microalgas para produção de Biodiesel.

${ }^{4}$ Acadêmico do Curso Superior de Tecnologia em Biocombustíveis, da Universidade Federal do Paraná. Atua em atividades desenvolvendo Processos Fermentativos e Enzimáticos para a produção de Etanol Biocombustível a partir de resíduos lácteos.

${ }^{5}$ Acadêmico do Curso de Agronomia, da Universidade Federal do Paraná, Setor Palotina. Atua em atividades de pesquisa relacionado a otimização de Processos Fermentativos para produção de Enzimas Fúngicas

${ }^{6}$ Acadêmica do Curso de Tecnologia em Biotecnologia, da Universidade Federal do Paraná, Setor Palotina. Atua em atividades de pesquisa desenvolvendo Processos Fermentativos para produção de Enzimas Fúngicas

Palavras-chave: Soro, Lactose, Hidrólise Ácida, Kluyveromyces Marxianus.

\section{Resumo}

Neste trabalho avalia-se um maior aproveitamento da lactose proveniente do soro de leite das indústrias de laticínios da Região Oeste do Paraná para produção de um produto que venha suprir, ao menos em parte, a necessidade de uma fonte renovável de biocombustíveis, o etanol. Para cada litro de soro são desperdiçados cerca de $50 \mathrm{~g}$ de lactose e $10 \mathrm{~g}$ de proteína, além de 0,5 a $0,7 \%$ de sais minerais com elevado valor nutricional e funcional, criando condições para poder pensar-se num processo de valorização do soro com simultânea redução da carga poluente e aumento da diversidade de oportunidades para agregar valor e aproveitamento dos resíduos de pequenos e médios laticínios. Muitas produtoras se interessam pela questão do álcool a partir desta fonte para abastecer as suas frotas e reduzir a logística de transporte, no entanto dependem de um custo, equiparando-se com o preço pago atualmente para outras empresas que aproveitam o soro. Pensando nesta realidade, 
desenvolveram-se testes experimentais com rotas econômicas para a produção de etanol a partir de processos fermentativos. Avaliou-se pré-tratamento químico para hidrólise da lactose e fermentação convencional e processo com leveduras que fermentam diretamente a lactose como a Kluyveromyces Marxianus, nas mesmas condições operacionais e nutricionais de fontes de micronutrientes e extratos proteicos. Determinou-se indiretamente por balanço estequiométrico a conversão da lactose em etanol, para isto, monitorou- se a produção de CO2, medindo a variação de massa do sistema. Através da evolução da fermentação, verificou-se as características do comportamento celular associado ao consumo de substrato e formação de produtos. Observou-se que é possível altas conversões de substrato e melhoria na produtividade do processo de produção de etanol. A melhor opção é por rota que utilize levedura com capacidade de realizar diretamente a assimilação de lactose e formação de etanol em uma única etapa, ao invés de pré tratamento químico, o qual não trouxe vantagens significativas para as rotas estudadas.

\section{Introdução}

Nas indústrias de laticínios, entre os principais efluentes encontra-se o soro provindo da produção de queijos. Soro é o nome dado ao líquido remanescente das etapas de precipitação e remoção da caseína do leite, durante a fabricação do queijo. As indústrias de laticínios o produzem diariamente em grandes quantidades. Para cada kg de queijo produzido gera-se, em média, $9 \mathrm{~kg}$ de soro. Por se tratar de um subproduto de baixo valor econômico, antigamente o soro era simplesmente lançado nos cursos d'água sem nenhum tratamento prévio. Embora várias possibilidades de utilização tenham sido pesquisadas nos últimos cinquenta anos, até o ano de 1995, quase metade do soro produzido em todo o mundo ainda era descartado como um efluente (SISO, 1996). Isto fez com que o soro se tornasse um sério problema ambiental, devido às grandes quantidades produzidas e ao seu alto teor de matéria orgânica, com DBO de 30000 a $50000 \mathrm{mgL}^{-1}$ (MAWSON, 1994). A formação do queijo é, deste modo, responsável pela geração de grandes quantidades de efluentes, constituindo-se um grave problema ambiental devido à sua elevada carga orgânica de difícil biodegradabilidade, sua alta Demanda Química de Oxigênio (DQO) dificulta significativamente a eficiência de qualquer tratamento de efluente.

A produção mundial de soro de queijo é de aproximadamente 120 milhões de toneladas anuais, o que gera 720.000 toneladas de proteínas (GIRALDO-ZUNIGA, et al., 2002). O Brasil é o sétimo maior produtor de queijos do mundo com uma produção total em 
2005 de 480.000 toneladas, gerando aproximadamente 4,3 milhões de toneladas de soro de queijo (USDA,2006).

A lactose está presente no leite e no soro, em média 5\% no estado molecular em solução verdadeira, com partículas de diâmetros inferiores a $1 \eta \mathrm{m}$. É formada por dois monossacarídeos, uma molécula de D-glicose e uma de molécula de $\beta$-D-galactose. O grupo no carbono anomérico da porção glicose não está envolvido na ligação glicosídica, ficando livre para reagir com agentes oxidantes, sendo assim a lactose considerada um açúcar redutor (BECKER, 2009).

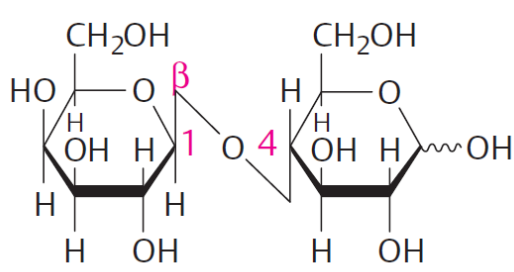

Figura 1: Estrutura molecular da Lactose na perspectiva de Haworth: Lactose: $\beta$-D-Galactopiranosil$(1 \rightarrow 4)$-D-glicopiranose(galactose + glicose) (LEHNINGER, 1980)

Com os crescentes preços dos combustíveis automotores tem-se chamado a atenção para a possibilidade de produzir etanol a partir de outras fontes renováveis. Neste contesto, o soro de queijo vem surgindo como uma alternativa viável na produção de etanol (DEMOTT, et. al., 1981; CHEN \& ZALL, 1982).

Um dos caminhos mais promissores é utilizar a lactose do soro como fonte de carbono para a produção de ácidos orgânicos por fermentação. A lactose não é usada diretamente nos processos fermentativos convencionais que empregam Saccharomyces cerevisiae. Apesar de a levedura Saccharomyces cerevisiae fermentar uma grande variedade de açúcares, não é capaz de metabolizar a lactose, devido à ausência da enzima $\alpha$ galactosidase (que hidrolisa este açúcar em glucose e galactose) e da permease da lactose, que permite a entrada da lactose para o interior das células. Isto só seria possível indiretamente através da glicose e da galactose produzidas pela hidrólise de sua molécula através da $\beta$-Dgalactosidase (obtida comercialmente) ou da hidrólise ácida a alta temperatura, geralmente a $150^{\circ} \mathrm{C}$ e curto tempo.

Outro aspecto em que os processos de fermentação da lactose são passíveis de melhoramento não se prende com o processo prévio enzimático ou ácido em si, mas com o microrganismo utilizado na fermentação alcoólica da lactose. O microrganismo mais utilizado é a levedura do gênero Kluyveromyces, que fermenta naturalmente este açúcar apresentando, 
no entanto, problemas de inibição por etanol. Apesar da possibilidade de utilizar uma rota mais simples, o problema maior reflete em altos volumes com baixa concentração de etanol.

A avaliação de alternativas para a produção de etanol por fermentação, se por rota prévia química, enzimática ou unicamente por levedura Kluyveromyces depende ainda das condições operacionais de temperatura, $\mathrm{pH}$ e suprimentos nutricionais para acelerar a fermentação.

Neste trabalho, quanto à matéria prima, utilizou-se soro em pó (Sooro), com alta concentração de lactose e soro líquido. Para ambos, empregou-se rotas envolvendo tratamento ácido a alta temperatura com correção do meio e posterior fermentação com S. cervisiae. Fermentação com Kluyveromyces e empregou lactose PA e igualmente como todos os demais houve correção de $\mathrm{pH}$, temperatura em torno de $35^{\circ} \mathrm{C}$ e suprimento nutricional com micronutrientes e extratos proteicos. Observou-se reações lentas para todos os processos. A opção pelo processo envolvendo Kluyveromyces mostrou-se mais eficiente, obtendo-se uma conversão de mais de $80 \%$ e produtividade maior.

\section{DESENVOLVIMENTO EXPERIMENTAL}

Matéria Prima:

O soro de leite in natura foi fornecido pelo Laticínio La Salle de Palotina e o soro em pó pela Sooro de Marechal Rondon. Os experimentos e análises foram executados no Laboratório da Universidade Federal do Paraná, Setor Palotina. Inicialmente, procedeu-se a determinação da concentração do soro de leite e estimativa da concentração inicial visando o acompanhamento da conversão de massa ao longo do tempo. Para determinação da concentração da lactose e estimativa da concentração inicial de substrato procedeu-se ao ajuste da curva de calibração pelo método dos mínimos quadrados de um modelo linear envolvendo absorbância e concentração de lactose PA. O método utilizado para obtenção da curva de calibração envolveu o preparo de uma solução padrão de $5 \mathrm{gL}^{-1}$ e sucessivas diluições, seguindo-se o procedimento para determinação de açúcares redutores através do método Espectrofotométrico com reagente DNS (MILLER, 1959). A equação (1) foi obtida das leituras a $540 \mathrm{~nm}$ com espectrofotômetro Edutec EEQ 9023.

$\mathrm{C}_{\text {Lactose }}\left(\frac{\mathrm{g}}{\mathrm{L}}\right)=2,658 \times \mathrm{ABS}_{540} \mathrm{x}$ fd $\quad R^{2}=0,993$ equação (1)

A equação 1 foi validada para amostras comerciais de leite e soro, sendo analisada amostras de soro após tratamento térmico por autoclavação, centrifugação e filtração. Obteve- 
se os teores de lactose calculados próximos aos reais observados na faixa de 4 a $5 \%$ para ambos os casos, Tabela 1.

Tabela 1:Validação do modelo para estimativas de concentração de lactose em leite e soro, para fatore

diluição de 20x. Concentração medida em termos de ART Lactose

\begin{tabular}{c|c|c|c}
\hline C lactose $\left(\mathrm{gL}^{-1}\right.$ & ABS & $f d$ & produto \\
\hline 53,80804 & 1,012 & 20 & soro \\
\hline 50,88369 & 0,957 & 20 & leite \\
\hline
\end{tabular}

Os processos de produção de etanol a partir da lactose envolveram a execução de quatro rotas, três rotas empregaram Sacharomyces cerevisiae comercial a 10\% em base seca, a quarta rota utilizou a levedura Kluyveromyces Marxianus. Nas três primeiras rotas, desenvolveu-se hidrólise ácida com temperatura controlada de $150^{\circ} \mathrm{C}$ em bloco digestor com $\mathrm{pH}$ em torno de 1,5 a 2,0. Posteriormente as amostras foram resfriadas e o $\mathrm{pH}$ elevado para 4,0. Para todas as amostras, antes da fermentação os meios foram supridos com sais minerais e extratos proteicos, visando acelerar o metabolismo celular. As tabelas 2 a 5 trazem uma síntese das rotas desenvolvidas.

Tabela 2: Rota 1 para Fermentação da Lactose em Etanol

Rota 1: Proposta para Conversão de Lactose em Etanol partir do soro líquido

\begin{tabular}{l|l}
\hline Pré-Tramento & Química com $\mathrm{HCl}$ e fermentação convencional \\
\hline Matéria Prima & Soro Líquido \\
\hline Hidrólise: & Acidificação até pH 1,$2 ; 4$ minutos a $150^{\circ} \mathrm{C}$ \\
\hline Correção $\mathrm{pH}$ & Até 4,0 com $\mathrm{NaOH}$ \\
\hline Correção do Meio & Micronutrientes e extrato de proteína \\
\hline Microrganismo & Levedura de panificação \\
\hline Condição Operacional da Fermentação & Temperatura de $32^{\circ} \mathrm{C}$ \\
\hline
\end{tabular}

Tabela 3: Rota 2 para Fermentação da Lactose em Etanol

\begin{tabular}{l|l}
\hline Rota 2: Proposta para Conversão de Lactose em Etanol partir do soro \\
\hline Pré-Tramento & Química com $\mathrm{HCl}$ e fermentação convencional \\
\hline Matéria Prima & Soro Líquido \\
\hline Hidrólise: & Acidificação até $\mathrm{pH} 1,2 ; 4$ minutos a $150^{\circ} \mathrm{C}$ \\
\hline Correção pH & Até 4,0 com $\mathrm{NaOH}$ \\
\hline Correção do Meio & Micronutrientes e extrato de proteína \\
\hline Microrganismo & Levedura de panificação \\
\hline Condição Operacional da Fermentação & Temperatura de $32^{\circ} \mathrm{C}$ \\
\hline
\end{tabular}

Tabela 4:Rota 3 para Fermentação da Lactose em Etanol

Rota 3: Proposta para Conversão de Lactose em Etanol partir do soro em pó

\begin{tabular}{l|l}
\hline Pré-Tramento & Química com $\mathrm{HCl}$ e fermentação convencional \\
\hline
\end{tabular}




\begin{tabular}{l|l}
\hline Matéria Prima & Soro em Pó, diluído a $50 \mathrm{gL}^{-1}$ \\
\hline Hidrólise: & Acidificação até $\mathrm{pH} 1,2 ; 4$ minutos a $150^{\circ} \mathrm{C}$ \\
\hline Correção $\mathrm{pH}$ & Até 4,0 com $\mathrm{NaOH}$ \\
\hline Correção do Meio & Micronutrientes e extrato de proteína \\
\hline Microrganismo & Levedura de panificação \\
\hline Condição Operacional da Fermentação & Temperatura de $32^{\circ} \mathrm{C}$ \\
\hline
\end{tabular}

Tabela 5: Rota 4 para Fermentação da Lactose em Etanol

\begin{tabular}{l|l}
\hline \multicolumn{2}{c}{ Rota 4: Proposta para Conversão de Lactose em Etanol partir da lactose PA } \\
\hline Pré-Tramento & Não há \\
\hline Matéria Prima & Lactose $\mathrm{PA}$, diluída a $50 \mathrm{gL}{ }^{-1}$ \\
\hline Hidrólise: & Acidificação até $\mathrm{pH} 1,2 ; 4$ minutos a $150^{\circ} \mathrm{C}$ \\
\hline Correção pH & Até 4,0 com $\mathrm{NaOH}$ \\
\hline Correção do Meio & Micronutrientes e extrato de proteína \\
\hline Microrganismo & Kluyveromyces Marxianus \\
\hline Condição Operacional da Fermentação & Temperatura de $32^{\circ} \mathrm{C}$ e tempo de 42,5 horas \\
\hline
\end{tabular}

\section{Preparo do Inóculo}

Amostras de levedura comercial de $S$. cerevisiae em pó foram conservadas em geladeira em baixa temperatura enquanto a levedura KluyveromycesMarxianus CCT 4086 cedida pelo Curso de Engenharia Química da Unioeste - Campus Toledo foi repicada em placas de petri com ágar PDA e mantida em estufa de crescimento biológico a temperatura a $28^{\circ} \mathrm{C}$. Posteriormente preparou-se vários tubos de ensaio com soluções de lactose PA e condições nutricionais corrigidas com fontes de nitrogênio, fósforo, proteínas e sais minerais. Os tubos foram autoclavados e posteriormente levados para inoculação em bancada sob condições assépticas empregando alça de platina e bico de bunsen. Após a inoculação, mediuse a densidade ótica inicial e incubou-se em estufa para utilização posterior. Diariamente a absorbância a $660 \mathrm{~nm}$ foi verificada, procurando observar o crescimento celular pela turbidez da amostra, partindo de 0,3 nm e chegando a um máximo de 1,6 nm em 48 horas. Tentativas de aumento da concentração foram feitas adicionando mais lactose PA. Para estimativa da concentração inicial de células procedeu-se a leitura em câmara de Newbauer da amostra diluída, possibilitando quantificar a concentração inicial nos biorreatores.

\section{Fermentação}

No caso da hidrólise ácida, tentativas a baixa temperatura resultaram dificuldade na conversão da lactose em glicose e galactose, optando-se por condições mais severas a tempos curtos. Após a hidrólise de amostras de soro em pó ou líquido, corrigiu-se o pH para 4,0 e adicionou-se nutrientes para fermentação com S. Cerevisiae a $10 \%$ em base seca. Em uma 
outra rota, inoculou-se em torno de $10 \mathrm{~mL}$ de solução repicada e previamente adaptada de KluyveromycesMarxianus CCT 4086 em solução de lactose PA. Monitorou-se para todas as rotas a evolução da formação de $\mathrm{CO}_{2}$ e perda de massa do sistema. Uma vez que as condições iniciais eram conhecidas, e com base na estequiometria da reação, determinou-se a converso da lactose em etanol.

\section{Resultados e discussão}

Para o caso da rota 1 , se considerando um crescimento associado a produção de etanol, verifica-se uma fermentação lenta, quase uma fase lag por 20 horas e com tendência a uma fase exponencial pequena após 20 horas de reação. Neste caso verifica-se que a possibilidade de aumentar o tempo de hidrólise ácida e melhorar a correção de nutrientes para aumentar a velocidade de reação.

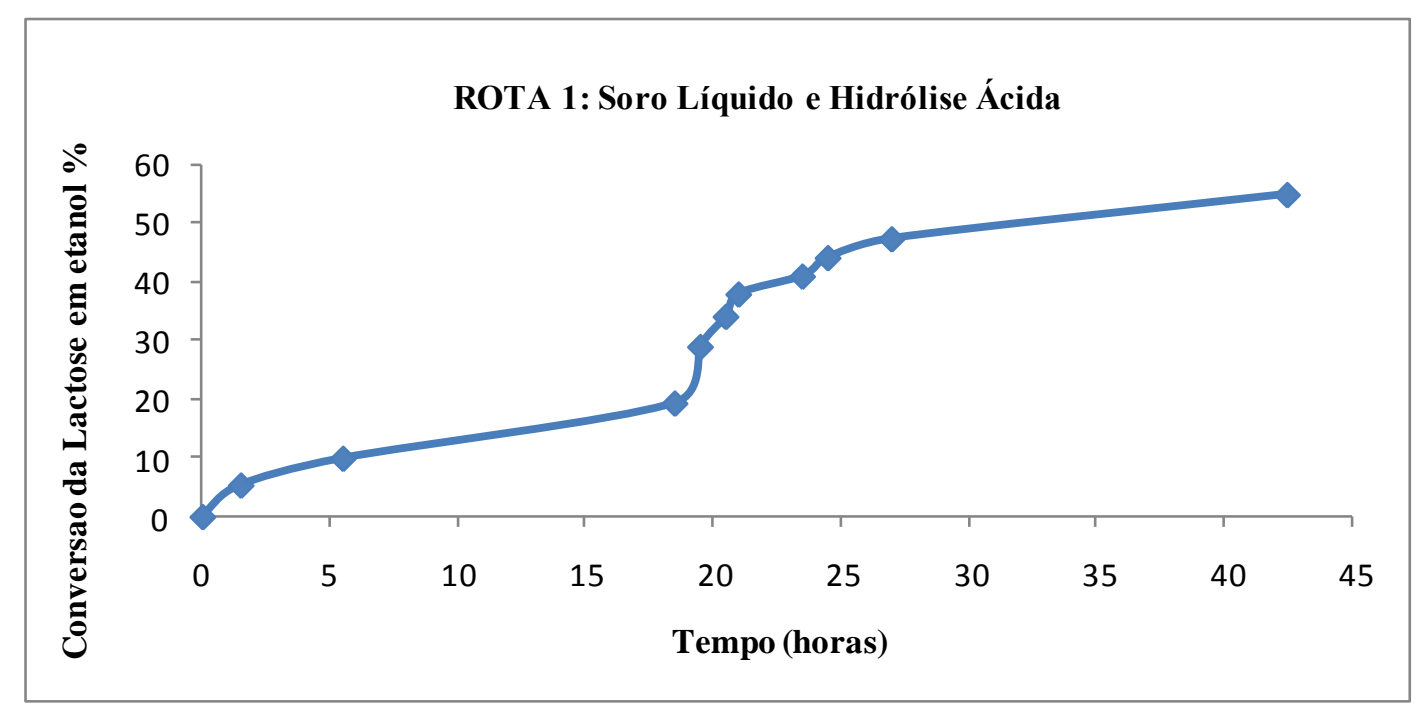

Figura 2: Fermentação com $S$. Cerevisiae após hidrólise ácida de soro líquido, evolução do processo foi determinado em função da conversão da lactose.

Para o caso da rota 2 , os resultados foram semelhantes com o da rota 1 , novamente, com uma tendência lenta no metabolismo de conversão de substrato e formação de produtos, neste caso o desempenho foi pior, mostrando que há uma limitação na hidrólise ácida, a sugestão seria melhorar a hidrólise aumentando o tempo a altas temperaturas e aumentar o suprimento de nutrientes para acelerar a fase inicial e diminuir a fase lag. 


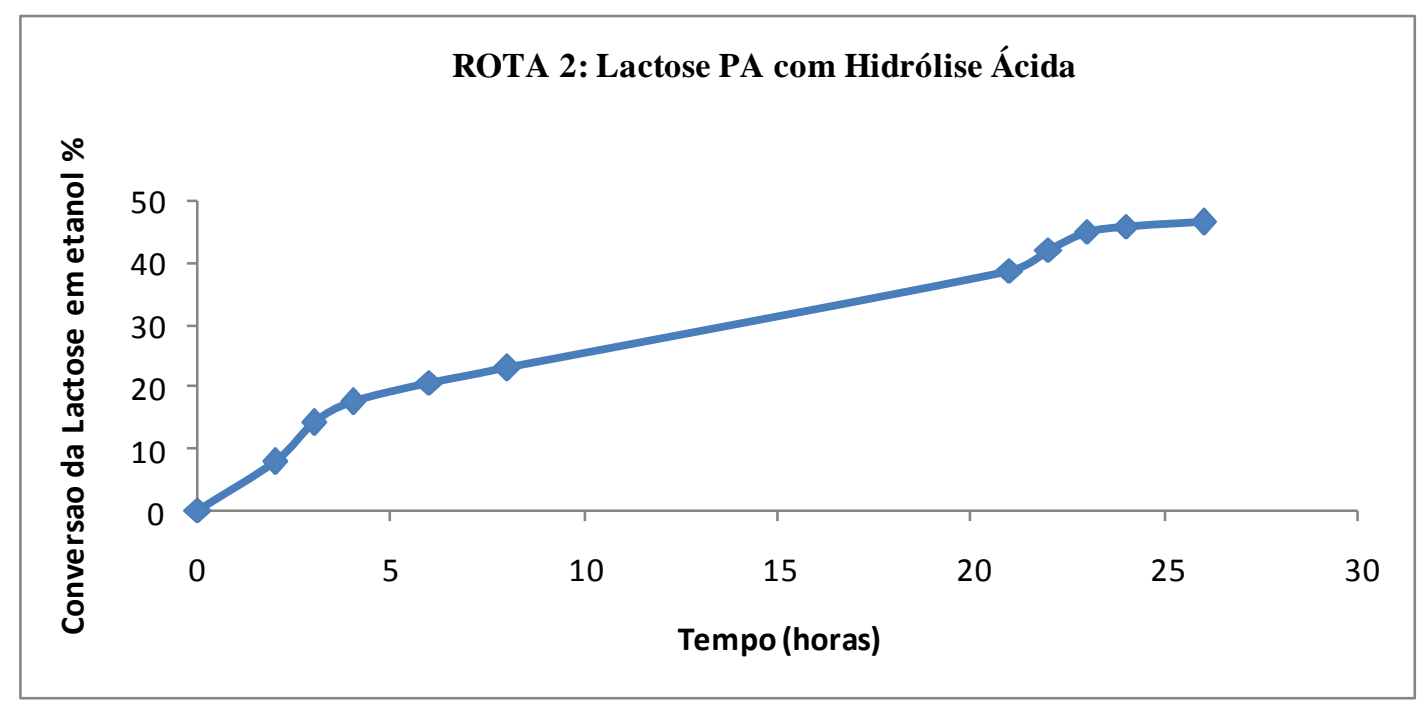

Figura 3: Fermentação com $S$. Cerevisiae após hidrólise ácida de uma solução de lactose PA. Evolução do processo foi determinado em função da conversão da lactose.

Situação semelhante a da rotas 2 e 3 pode ser observada com a rota 3. Se admitirmos crescimento associado à formação de produtos, neste caso, é nítida a fase lag observada de quase 4 horas, com posterior fase de aceleração. Neste caso o soro em pó apresenta maior quantidade de nutrientes do que a Lactose, favorecendo a uma aceleração no metabolismo, o decréscimo da velocidade de conversão pode ser explicada pela redução de concentração de lactose, ou da fonte de carbono. Uma vez que a velocidade de reação depende da concentração de substrato é natural que fases menos acentuadas ocorram após a fase de aceleração.

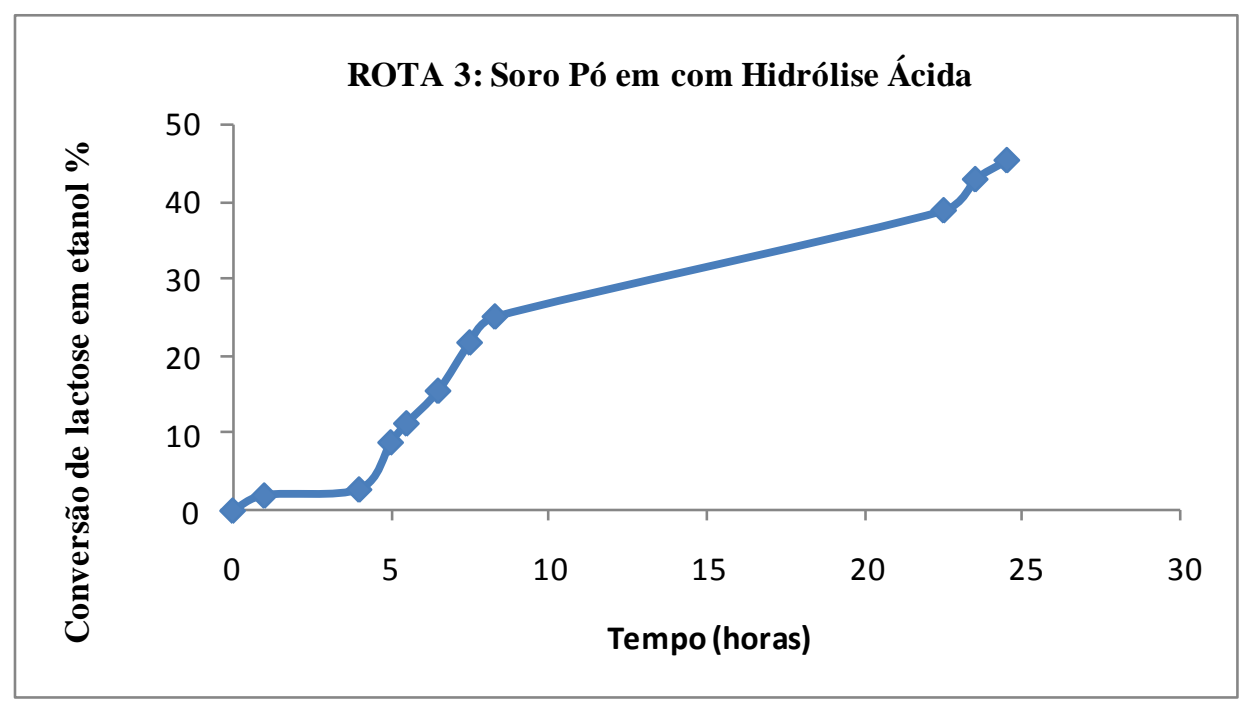

Figura 4: Fermentação com S. Cerevisiae após hidrólise ácida de uma solução de soro em pó. Evolução do processo foi determinado em função da conversão da lactose. 
Na Figura observa-se a conversão da lactose em etanol. Verifica-se ausência de fase lag e um comportamento logístico para a conversão, consequência do comportamento do crescimento celular associado. Apesar da reação ser lenta, a conversão é satisfatória a períodos longos. Pode-se reduzir este tempo e melhorar a velocidade de reação, aumentando a concentração do inóculo inicial e aspectos nutricionais, aliando a presença de outras leveduras com menor grau de inibição.

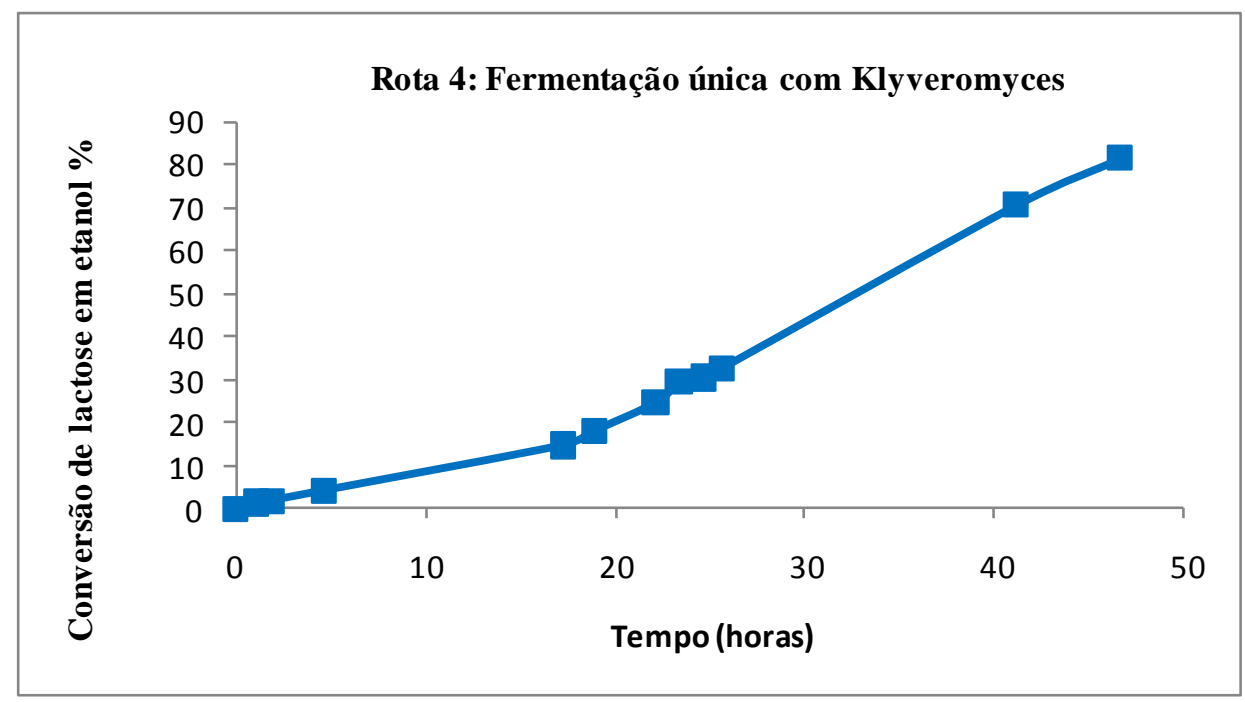

Figura 5: Fermentação com Kluyveromyces Marxianus Evolução do processo foi determinado em função da conversão da lactose.

\section{Conclusões}

O desempenho das rotas que empregaram hidrólise ácida permitiram mostrar que o tempo de hidrólise é um fator a ser otimizado. Neste caso aliando-se o aspecto nutricional pode-se levar a maiores velocidades de reações e finalmente a conversões próximas a 100\%, no entanto, em termos de processo, a produtividade de todas as etapas seria baixo se comparado a outras alternativas que não empregam rotas químicas. A utilização de leveduras que fermentam diretamente a lactose permite altas conversões e produtividades. Resultados mostraram que se bem adaptadas e com concentrações adequadas, leveduras do gênero Kluyveromyces são adequadas para o processamento, possibilitando ainda que co-culturas não sintam tanto o processo de inibição pelo etanol. 


\section{Referências}

1. BECKER, D. E., (2009) Preoperative Medical Evaluation: Part 1: General Principles and Cardiovascular Considerations. Anesthesia Progress, Richmond, v. 56, n. 3, p. 92 - 103.

2. CHEN, H. C.; ZALL, R. R., (1982), Continuous fermentation of whey into alcohol using an attached film expanded bed reactor. Process Biochemistry, Vol. 17, 1, p.20-25.

3. DEMOTT,B.J.;DRAUGHON, F. A; HERALD, P.J., (1981), Fermentation of lactose in direct-acid-set cottage cheese whey. Journal of Food protection, Vol. 44, n.8, p. 588-590.

4. GIRALDO-ZUNIGA, A. D. et al. Propriedades funcionais e nutricionais das proteínas do soro de leite. Revista do Instituto de Laticínios Cândido Tostes , v. 57, n. 325, p. 35-46, 2002

5. LEHNINGER, A. L., (1980). Fundamentos de bioquimica. São Paulo: Sarvier, 463p.

6. MAWSON, A. J. Bioconversions for Whey Utilization and Waste Abatement. Bioresource Technology, v.47, n.3, p.195-203. 1994.

7. MILLER, G. L. Use of dinitrosalicylic acid reagent for determination of reducing sugars. Analytical Chemistry, v.31, n.3, p.426-428, 1959.

8. SISO M. I. G. The biotechnological utilization of cheese whey: a review BioresourceTechnol., v. 57, p. 1-11, 1996.

9. USDA, United States Department of Agriculture, Disponível em: 〈http://www.usda.gov>, Acesso em junho de 2013. 